\title{
Analyzing Varieties of Agricultural Data Using Big Data Tools Pig
}

\author{
BANKIM L. RADADIYA ${ }^{1}$ and PARAG SHUKLA ${ }^{2 *}$ \\ ${ }^{1}$ Navsari Agricultural University - Navsari - Gujarat India. \\ ${ }^{2}$ Department of MCA, Atmiya Institute of Technology \& Science, Rajkot - 360005, India.
}

\begin{abstract}
Day by day, data is growing rapidly. Analysis of the data is necessity. As per recent survey data generated in last 2 years is more than the data created in entire previous history of human. Data created in different form and in diversified manner. It can be structured, it can be semi-structured, or it can be unstructured. To analyze diversified by agricultural data we can use the tools of Big Data like Pig. Using Pig, we can analyze varieties of data. Pig is a platform for analysis of data. Biggest advantage of Pig is it can process any diversified data very quickly and allows us to use user defined functions. Use Case of Pig is ETL. It is used to extract the data from sources then after applying transformation we can load it into the data warehouse. We will do analysis of state wise proportion circulation of Numeral of operative properties for all societal collections in 2005-06 and 2010-11 using Pig.
\end{abstract}

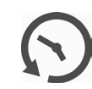

Article History

Received: 04 December 2017

Accepted:11 December 2017

\section{Keywords}

Analysis, Pig,

Varieties,

Agricultural data,

Big Data Tools,

Structured,

Semi-Structured,

Unstructured.

\section{Introduction}

Nowadays, data is growing very speedy. Analysis of the data is necessity for the many organization. As per recent survey data generated in last 2 years is more than the data created in entire previous history of human. Data created in different form and in diversified manner. It can be structured, it can be semi-structured, or it can be unstructured. To analyze diversified by agricultural data we can use the tools of Big Data like Pig. Using Pig, we can analyze varieties of data. Pig is a platform for analysis of data. Biggest advantage of Pig is it can process any diversified data very quickly and allows us to use user defined functions. Use Case of Pig is ETL. It is used to extract the data from sources then after applying transformation we can load it into the data warehouse.

Here, in this study we analyzed verities of agricultural data using the big data tools Pig.

\footnotetext{
CONTACT Parag C. Shukla paragshukla007@gmail.com 9 Department of MCA, Atmiya Institute of Technology \& Science, Rajkot - 360005, India.

(c) 2017 The Author(s). Published by Techno Research Publishers

This is an 6 Open Access article licensed under a Creative Commons Attribution-NonCommercial-ShareAlike 4.0 International License (https://creativecommons.org/licenses/by-nc-sa/4.0/), which permits unrestricted NonCommercial use, distribution, and reproduction in any medium, provided the original work is properly cited.

To link to this article: http://dx.doi.org/10.13005/ojcst/10.04.16
} 
What is Pig?

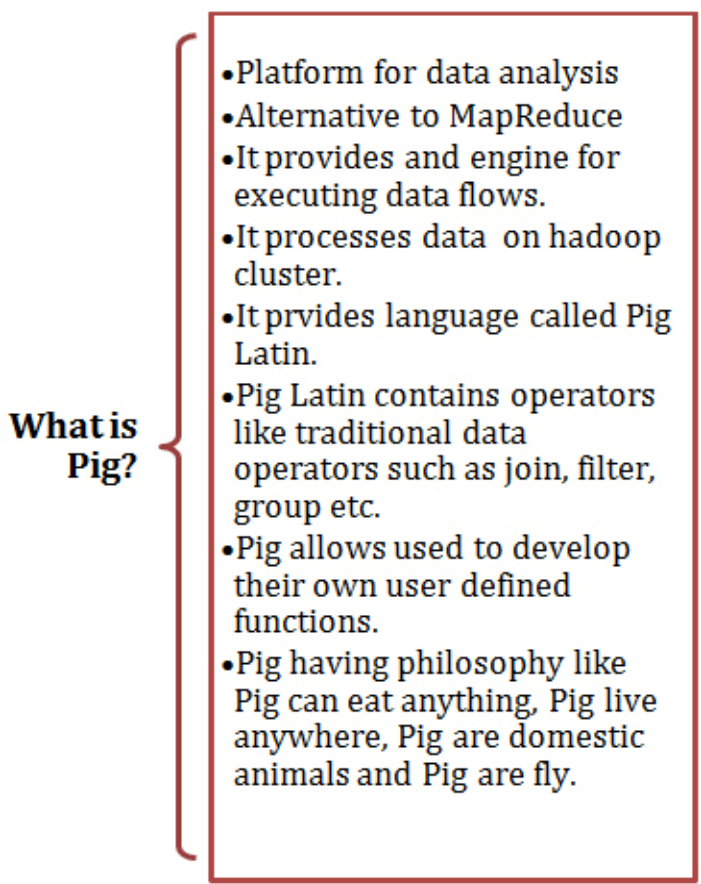

Fig.1: What is Pig?

Analysis of Structured Agricultural Data Using Pig

To analyze structured data, first we must identify the source of data. Source of structured data can be
Why Pig?\& What Pig Supports?

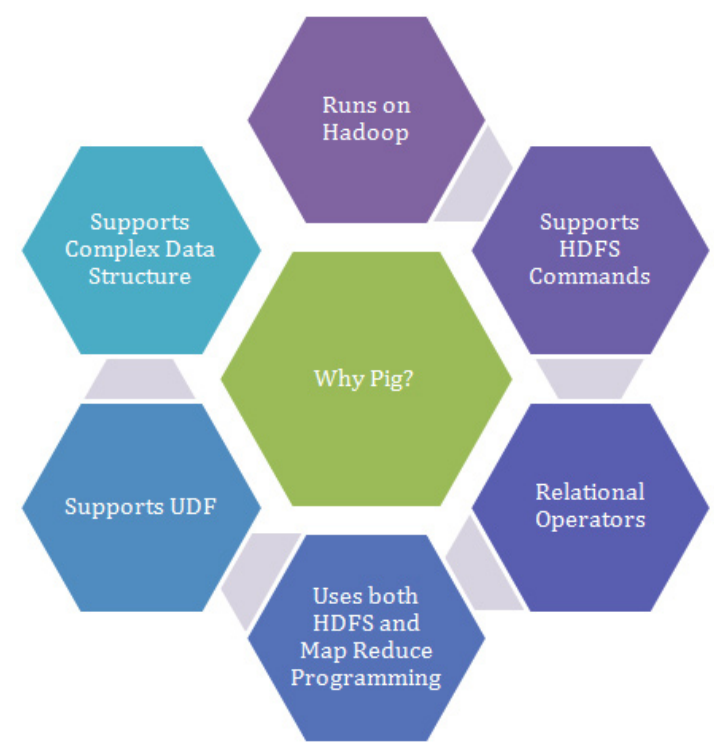

Fig.2: Why Pig? \& What Pig Supports?

any RDBMS like oracle, SQL Server, DB2, MySQL, Spreadsheets or OLTP Systems. Following are the source of structured data.

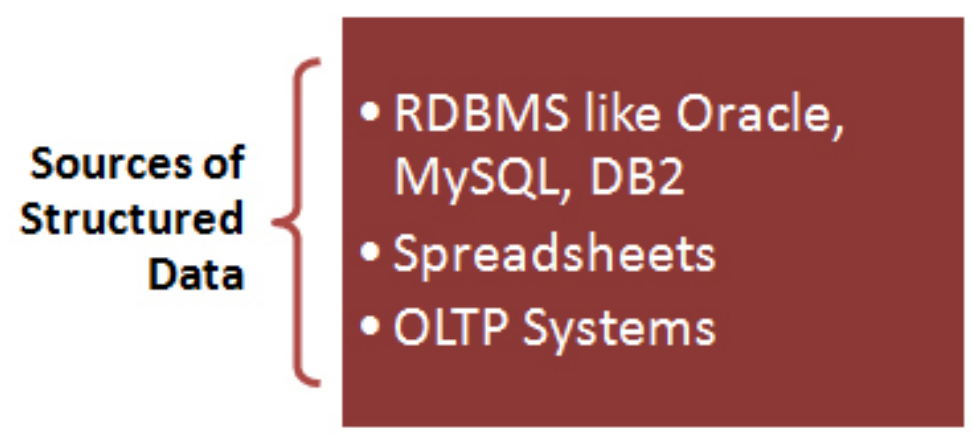

Fig.3: Sources of Structured Data

\section{Step-1 Load the structured data}

We took the data of state wise proportion circulation of Numeral of operative properties for all societal collections in 2005-06 and 2010-11 from government website ${ }^{1}$.
Once retrieve the comma separated values file from government website, we copied the file on linux platform. Once we copied on linux then we moved the same file on HDFS platform. Following is command to move the file from linux root directory 
to HDFS directory named PARAG. CopyFromLocal command is used to move the file from linux directory to HDFS directory.

\section{Arotessandoox:}

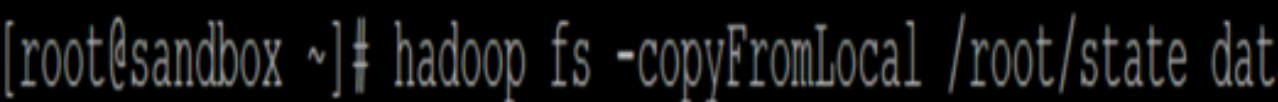 \\ $1 \mathrm{~d}$}

After moving the file from linux root directory to HDFS directory, we can load the data on Pig using Grunt shell

STAPE DATA = LOAD '/PARAG/state_data.CSV' USING PigStorage(',') AS (SR:INT, STATE:CHARARRAY, CENSUS MARGINAL 05: ELOAT, CENSUS SMALL 05: FLOAT, CENSUS SEMI NEDIUM 05: ELOAT, CENSUS MEDIONM 05: ELOAT, CENSUS LARGE 05: RLOAT, CENSUS MARGINAL 10: FLOAT, CENSUS SMALL 10: FLOAT, CENSUS SEMI NEDIOM 10: FLOAT, CENSUS NEDIONM 10: ËLAT, CENSUS__LARGE_ 10 : FLOAT । 
Step-2 Display the loaded data

We can use dump statement to display the data in Grunt Shell.

\section{grunt> DUMP STATE DATA;}

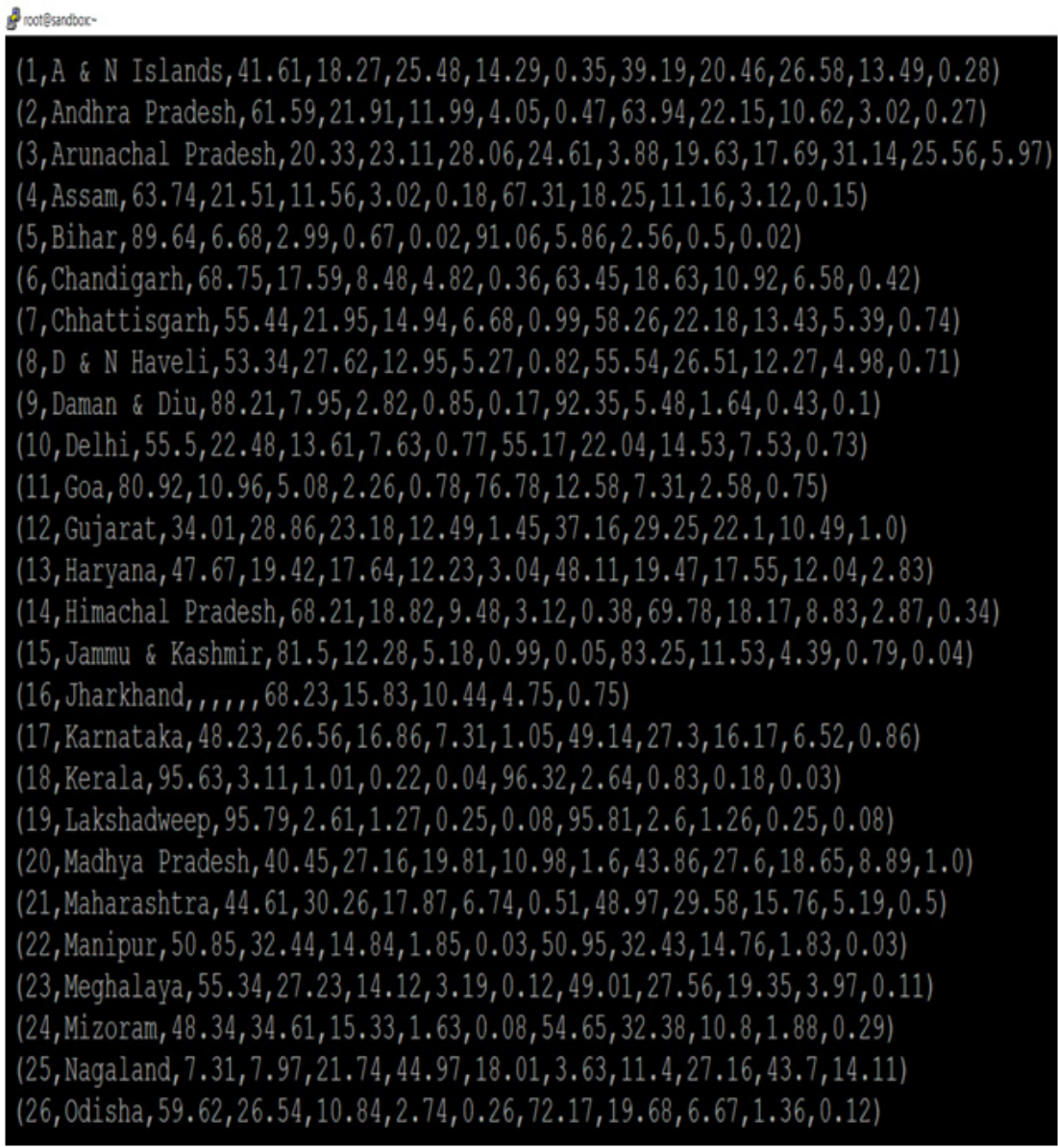

Fig.4: State wise proportion circulation of Numeral of operative properties

Step-3 Filter Specific Data

For analysis of any data we can use filter or aggregate functions. Here, we are filtering the specific data from state Gujarat.

\section{SPECIFIC_DATA $=$ FILTER STATE_DATA BY STATE $==$}

Ponteraction-

grunt> SPECIPTC DATA = FILTER STARE DATA BY STARE =- 'Gujarat';

grunt> DOMP SPECIRTC DAMA;

$(12$, Gujarat, $34.01,28.86,23.18,12.49,1.45,37.16,29.25,22.1,10.49,1.0$

grunt> 
Finding all state data which census_marginal of 2005

is more than 50
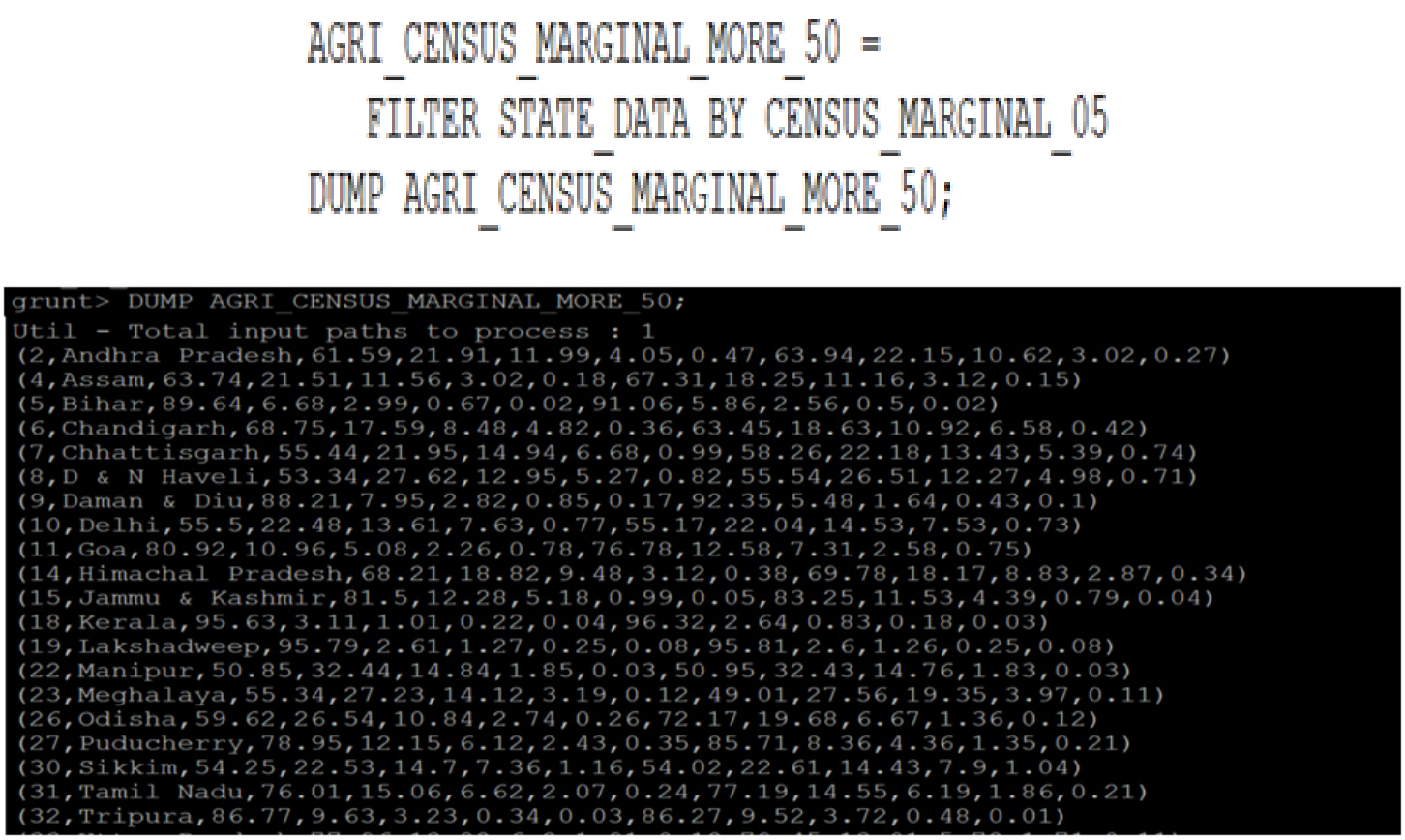

Fig.5: State wise data of 2005 which census marginal is more than $\mathbf{5 0}$

Finding all state data which census_small of 2005

is more than 30
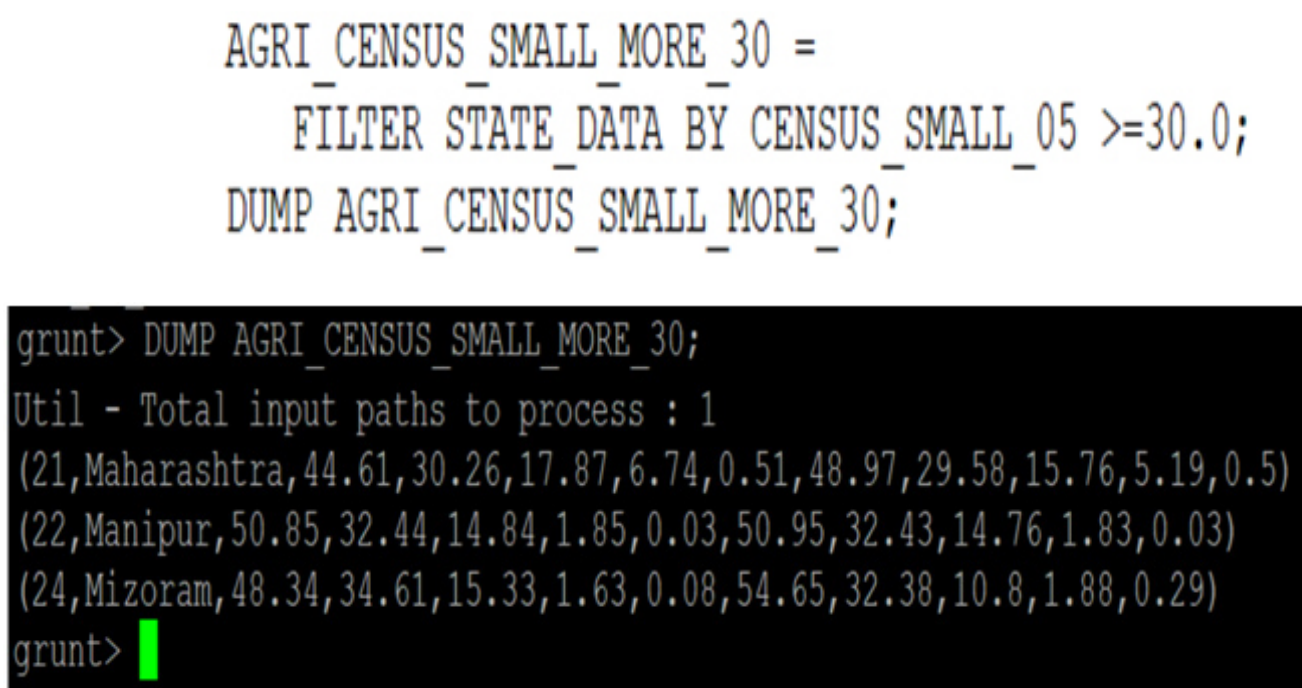
Finding all state data which census_marginal of 2010 is more than 80
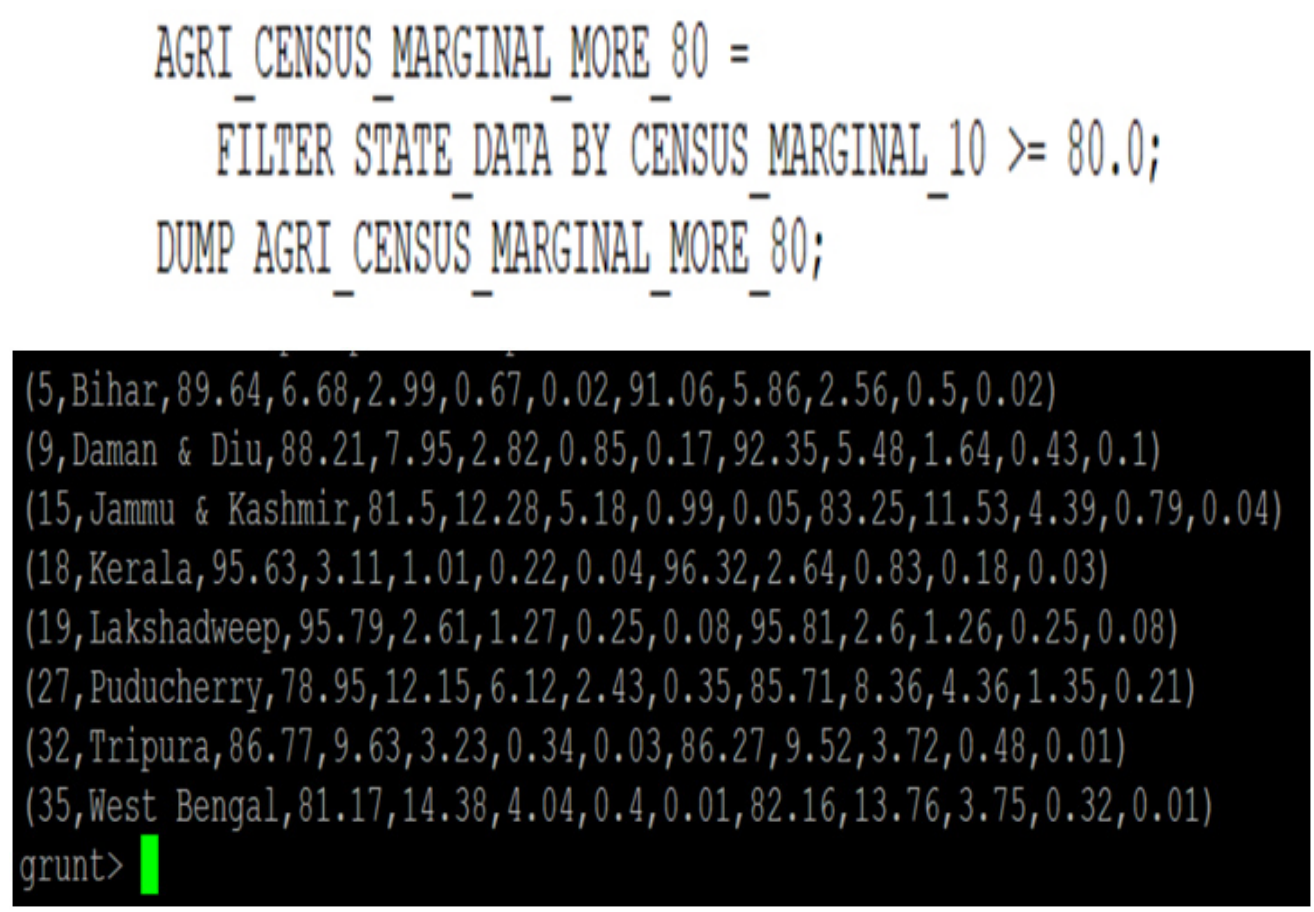

Fig.6: State wise data of 2010 which census marginal is more than 80

Finding all state data which census_small of 2010 is more than 30

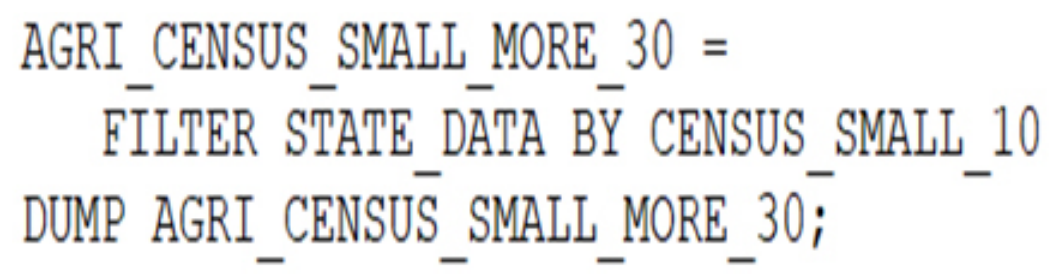

Util - Total input paths to process : 1

(22, Manipur, 50.85, 32.44,14.84, 1.85,0.03, 50.95, 32.43, 14.76, 1.83,0.03) (24, Mizoram, 48.34, 34.61,15.33, 1.63,0.08, 54.65,32.38, 10.8, 1.88, 0.29) grunt>

Analysis of Unstructured Agricultural Data Using Pig

\section{Conclusion}

We did analysis of agricultural data of state wise proportion circulation of Numeral of operative properties for all societal collections in 2005-06 and 2010-11 using Pig. We analyzed structured agricultural data using Pig. As we know that day by day requirement of analysis of the data is increasing rapidly. To demonstrate the use of analysis using big data tools Pig we used the government agricultural data and did the analysis of data. 
Analysis of the data is necessity for the many organization. Data created in different form and in diversified manner. It can be structured, it can be semi-structured, or it can be unstructured. To analyze diversified by agricultural data we can use the tools of Big Data like Pig. Using Pig, we can analyze varieties of data. Pig is a platform for analysis of data. Biggest advantage of Pig is it can process any diversified data very quickly and allows us to use user defined functions. Use Case of Pig is ETL. It is used to extract the data from sources then after applying transformation we can load it into the data warehouse.

\section{Acknowledgment}

We wish to thank Open Government Data Platform (OGD) for providing data for analysis \& sincere thanks to our mentor.

\section{References}

https://data.gov.in/resources/state-wisepercentage-distribution-number-operationalholdings-all-social-groups-during Apache Pig, https://pig.apache.org/ Apache Pig Architecture and components of Pig [online resource]https://www.tutorialspoint. com/apache_pig/apache_pig_architecture. htm

4 Pig Philosophy, https://pig.apache.org/ philosophy.html

5 Hive Vs Pig [online resource] http://www. bigdataanalyst.in/hive-vs-pig/

6 Big Data and Analytics - Wiley Publication, Seema Acharya, Subhashini Chellapan

7 Dr. Birendra Goswami, Pradip Kumar Chandra "The Evolution Of Big Data As A Research And Development" International Journal of Scientific Research and Engineering Studies (IJSRES) Volume 2 Issue 3, March 2015 ISSN: 2349-8862

8 Online Resource https://data.gov.in/ 